\title{
Examining the Link Between Domestic Violence Victimization and Loneliness in a Dutch Community Sample: A Comparison Between Victims and Nonvictims by Type D Personality
}

\author{
Maarten J. J. Kunst • Marja J. H. van Bon-Martens
}

Published online: 16 April 2011

(C) The Author(s) 2011. This article is published with open access at Springerlink.com

\begin{abstract}
The current study investigated whether differences in loneliness scores between individuals with a distressed personality type (type D personality) and subjects without such a personality varied by domestic violence victimization. Participants $(N=625)$ were recruited by random sampling from the Municipal Basic Administration of the Dutch city of 's-Hertogenbosch and were invited to fill out a set of questionnaires on health status. For this study, only ratings for domestic violence victimization, type D personality, feelings of loneliness, and demographics were used. Statistical analyses yielded main effects on loneliness for both type D personality and history of domestic violence victimization. Above and beyond these main effects, their interaction was significantly associated with loneliness as well. However, this result seemed to apply to emotional loneliness in particular. Findings were discussed in light of previous research and study limitations.
\end{abstract}

M. J. J. Kunst $(\bowtie)$

Faculty of Law, Institute for Criminal Law and Criminology,

Leiden University,

Room C1.23, P.O. Box 9520, 2300 RA Leiden, The Netherlands

e-mail: m.j.j.kunst@law.leidenuniv.nl

M. J. H. van Bon-Martens

Regional Health Service Hart voor Brabant,

's-Hertogenbosch, The Netherlands

M. J. H. van Bon-Martens

Scientific Centre for Care and Welfare, Faculty of Social Sciences,

Tilburg University,

Tilburg, The Netherlands
Keywords Domestic violence victimization · Type D personality $\cdot$ Loneliness

\section{Introduction}

Domestic violence encompasses many different types of violence within the home, such as child (sexual) abuse and neglect, intergenerational transmission of violence, violence between intimate partners, and witnessing inter-parental violence (Winkel 2007). It appears to be epidemic in size in many Western countries (e.g., Ruiz-Pérez et al. 2007), although prevalence rates observed in empirical research may vary substantially due to differences in definitions, measuring methods, and study sample characteristics. In the Netherlands, lifetime prevalence estimates of domestic violence lie between 29\% (Römkens 1997) and 45\% (Van Dijk et al. 1998). Twelve month prevalence, by contrast, appears to lie just above 4\% (Kunst et al. 2010).

Prevalence rates of domestic violence are even more alarming when its potential consequences for victims are considered. Among other things, domestic violence has been associated with a wide array of adverse physical (e.g., Coker et al. 2000), social (e.g., Staggs et al. 2007), and especially psychological consequences (e.g., Zlotnick et al. 1998). However, despite the well-documented relationship between domestic violence and negative psychological outcomes, in the majority of studies the independent effect of domestic violence seems to explain only a marginal proportion of the variance in victims' well-being after adjusting for potential demographic confounders in statistical analyses (e.g., Wolfe et al. 2003; Kitzmann et al. 2003; Nurius et al. 2003). Therefore, new research should explore 
which factors determine the impact of domestic violence on victims' well-being.

Type D Personality as a Risk Factor for Psychological Maladjustment to Domestic Violence

A number of recent studies suggests that an important role in the onset of mental health problems in victims of domestic violence is played by personality characteristics (e.g., Scott and Babcock 2010). To further develop this body of research, this study focused on one specific personality type: distressed personality type (type D personality). Type D personality is characterized by increased levels (i.e., above a pre-determined cut-off score) of both negative affectivity (NA) and social inhibition (SI). $\mathrm{NA}$ is a trait characteristic and involves, among other things, the stable tendency to experience negative emotions (e.g., Watson and Clark 1984), negative self-evaluations, and oversensitivity to adverse stimuli (e.g., Watson and Pennebaker 1989). When exposed to stressful events, people with high levels of NA tend to respond more intensely than others (e.g., Zeidner 2006). However, NA alone appears to be insufficient for development of negative outcomes. Several studies suggest that individual differences in emotion-regulation strategies are vital to the course of negative emotions experienced in the aftermath of stressexposure (e.g., Tull et al. 2007). One maladaptive emotionregulation strategy that has often been suggested to enhance the adverse influence of NA on successful coping with stressful conditions is SI (e.g., Denollet et al. 1996; Denollet et al. 1995). SI is another personality trait and involves the stable tendency to inhibit emotions and behaviour in social interactions to avoid disapproval by others, despite the presence of a need for companionship (Asendorpf 1993). According to type D scholars, particularly the combination of high levels of NA and high levels of SI is likely to be associated with adverse outcomes, as "it is not the experience of negative emotions per se, but rather the chronic psychological distress that results from holding back negative emotions, that is likely to affect (...) health" (Denollet et al. 1995, p. 583). How this combination of two personality traits affects wellbeing after stress exposure remains a largely unexplored topic, though.

Loneliness as an Intermediate Between Type D Personality and Mental Health

Based on the definition of SI, one might argue that the SI component of type D personality acts as an obstacle to form stable social relationships. Type Ds may therefore fail to fulfill the innate human need to belong. When having to deal with negative life events or conditions (e.g., domestic violence) and when emotional support and companionship from others is most needed, this failure may leave them at risk of experiencing a sense of loneliness. Loneliness represents a distressful affective state in which one holds the undesired perception of having few social relationships and being isolated from others (De Jong Gierveld 1987; Peplau and Perlman 1982). It has been conceptualized as the opposite of belongingness or embeddedness (De Jong Gierveld et al. 2006) and is often distinguished in two categories: emotional loneliness and social loneliness. The former primarily reflects perceived lack of sufficient dyadic attachment relationships and may therefore be conceived as an individual level category of loneliness, while the latter represents perceived disconnectedness to larger social networks that provide the individual with a sense of social integration, such as peer groups, school, work, and the community as a whole (e.g., Chipuer 2001; Vaux 1988; Weiss 1973, 1974).

Feelings of loneliness may be very unpleasant for the individual who experiences them, but should not be considered as a disease in themselves. Rather, they involve a risk for mental illness (Hawthorne 2008), particularly in conjunction with stress exposure (cf. Jones et al. 2005). A recent study provided initial support for this supposition with regard to domestic violence victimization (Kunst et al. 2010). In this study, impact of domestic violence victimization on self-reported mental health problems varied by level of loneliness. More specifically, victims with high levels of loneliness reported more mental health problems than victims with low levels of loneliness and nonvictims (with high or low levels of loneliness). When these findings are considered in the light of the proposed link between type D personality and loneliness, one might speculate that the impact of domestic violence victimization on mental health depends on loneliness, but particularly for subjects with type D personality. After all, type Ds are the ones most likely to develop loneliness in response to domestic violence (see Fig. 1).

However, before testing the empirical validity of this model, it seems reasonable to explore whether the speculated association between type D personality and loneliness exists in the first place.

\section{The Current Study}

Given the aforementioned, the current study investigated associations between domestic violence victimization, type D personality, and loneliness. Its purpose was twofold. First, we intended to explore whether mean loneliness scores between type Ds and nontype Ds differed by victim status (i.e., victim versus no victim). We expected that victims with type D personality and nonvictims without type D personality would report the highest and lowest 
Fig. 1 Relationship between domestic violence, type D personality, loneliness, and mental health problems

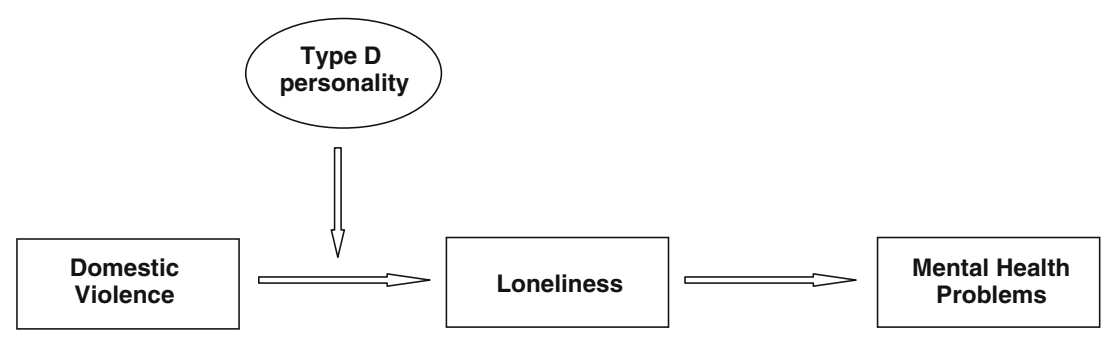

scores, respectively. Intermediate levels of loneliness were expected for victims without type D personality and type Ds without history of domestic violence. Second, we aimed to reveal whether the interaction term of domestic violence victimization and type $\mathrm{D}$ personality was associated with loneliness. If an interaction effect would be observed, this would indicate that victims with type $\mathrm{D}$ personality run an increased risk (i.e., above and beyond the cumulative effect of victimization and type D personality) of suffering from loneliness. We hypothesized that such an interaction effect is most likely to exist for emotional loneliness, as domestic violence victimization may be interpreted to reflect the destruction of the close bond between victim and perpetrator (cf. Swick 2008) and not so much a decrease in connections with networks outside the home.

\section{Methods}

Procedure and Participants

Study data were retrieved from the 2005 Hart voor Brabant Public Health Survey, which was conducted in 29 municipalities across the central part of the Dutch province of Noord-Brabant. As measures on NA and SI had been administered exclusively in the municipality of 's-Hertogenbosch, only respondents living in this city were eligible for inclusion. 's-Hertogenbosch is the capital of the province of Noord-Brabant and currently has approximately 140,000 inhabitants. Potential participants were randomly selected from the population of 's-Hertogenbosch between 18 and 65 years old through the Municipal Basic Administration and were sent a postal survey in the fall of 2005. A personal log on code was included for those who preferred to fill out the questionnaire through the internet. If necessary, reminders were posted 3 and 6 weeks after initial mailing. Participation was voluntary. Six hundred and sixty of those approached (47.2\%) responded (472/660, $71.5 \%$ by mail and 188/660, 28.5\% through the internet). The study was performed under the Dutch Public Health Preventive Measures Act of 1990 (Wet collectieve preventie volksgezondheid 1990) and was approved by the board of directory of the Regional Health Service Hart voor Brabant.
Measures

Background Characteristics The data set contained a huge amount of information on participants' socio-demographic background. For the current study, a limited number of background variables was described: age, gender, education level (i.e., master's or bachelor's degree versus other), ethnic background (Dutch versus other), and marital status (married or cohabitating versus other), having children under the age of 18 in the household (yes versus no), and employment status (i.e., holding a paid job versus other). The latter two variables were included as covariates, because previous studies suggest that these may act, in addition to demographics, as potential confounders when predicting loneliness (e.g., Lauder et al. 2004).

Domestic Violence Victimization To measure domestic violence victimization, participants were asked to indicate whether they had ever fallen victim to psychological/ emotional, physical, or sexual violence. Each category was accompanied by several examples. Participants were allowed to indicate more than one category. Item wording was reviewed by the Dutch national epidemiology workgroup. Participants who reported at least one history of violence were requested to answer several additional questions. For the current study, questions on acquaintance with the perpetrator(s) and location of victimization were used to create a dichotomous variable representing domestic violence victimization (defined as an act of violence perpetrated in the home by members of the family circle, including partners or ex-partners, children, other relatives, and close friends). This strategy followed upon previous research into domestic violence victimization in the Netherlands (see Kunst et al. 2010) and elsewhere (e.g., Okour and Hijazi 2009).

Type D Personality Type D personality, negative affectivity, and social inhibition were assessed by the Type D Scale 14 (DS14; Denollet 2005). The DS14 comprises two subscales: the NA subscale and the SI subscale. Both subscales contain seven items. Items need to be answered on a 5-point Likert scale ranging from 0 (false) to 4 (true). In accordance with previous victim studies (Kunst et al. 
2009,2011 ), a pre-determined cut-off score of $\geq 10$ on both subscales was used to classify participants as type D. Emons et al. 2007 have shown that the DS14 items have the highest measurement precision around this cut off. The subscales of the DS14 have high internal consistency and good test-retest validity over a three-month period (Denollet 2005). In the current study, the DS14 showed excellent internal consistency reliabilities, with Cronbach's $\alpha=0.88$ for both subscales.

Loneliness The Loneliness Scale (LS; De Jong Gierveld and Kamphuis 1985) was used to map feelings of loneliness. This instrument consists of 11 items: five items are positively worded and assess feelings of belongingness, six are negatively phrased and regard aspects of missing relationships. Response categories are: no, more or less, and yes. The no category is coded as zero, while both the more or less and the yes category are coded as one. The rationale behind this strategy is that many people are reluctant to admit social network deficits (Dykstra et al. 2005). The LS measures severity of loneliness. However, item scores can be used to compute total scores for emotional (six items) and social loneliness (five items) (De Jong Gierveld et al. 2006). As the two subscales correlated substantially in this study $(r=0.62, p<0.001)$, a principal components analysis with varimax rotation was conducted to ensure that LS items measured two independent constructs. Factors were extracted using scree plot inspection and identifying factors with eigen values greater than 1.0. Results confirmed the existence of a two-factor solution. The two factors accounted for $56.4 \%$ of the total variance, with the emotional loneliness items loading on the first factor $(>=0.58)$ and the social loneliness items loading on the second factor $(>=0.57)$. Psychometric properties of the LS have proven to be satisfactory in several Dutch samples (Van Tilburg and De Leeuw 1991). Internal consistency reliability was Cronbach's $\alpha=0.90$ for the total LS score, 0.85 for the emotional loneliness subscale and 0.78 for the social loneliness subscale.

\section{Statistical Analyses}

Means, standard deviations, and frequencies were computed to describe background variables. Next, subjects were differentiated by type D personality and victim status. A group variable was created to represent the four possible combinations: type Ds with history of domestic violence, type Ds without history of domestic violence, nontype Ds with history of domestic violence, and nontype Ds without history of domestic violence. Independent $t$ tests and chi square analyses, as appropriate, were conducted to compare the four groups on background variables and to estimate the effect size of the group variable. Then an one-way ANOVA was performed to detect between-groups differences in total loneliness scores when adjusting for observed background differences. Levene's test indicated that the assumption of homogeneity of variance between groups was violated. However, this was not deemed problematic, as the larger relative variance occurred in the largest group (Tabachnick and Fidell 2007). This did indicate, though, that ANOVA would produce conservative results. Post-hoc Tukey HSD tests with Bonferroni correction (alpha level should be $p<$ 0.008 ) were employed to locate group differences on the LS. Finally, a two-way between groups MANOVA was run to test for the significance of the association between the interaction term of domestic violence victimization and type D personality and loneliness subdimensions. MANOVA works best when dependent variables are highly negatively correlated and works reasonably well with moderate correlations that approximate $|<0.6|$ (Tabachnick and Fidell 2007). Given the correlation of 0.62 between the two LS subscales, this condition was fulfilled for our data. Since the assumption of homogeneity of variancecovariance matrices was violated, Pillai's Trace (Olson 1979) was used to determine whether the mean centroids for the three conditions (domestic violence victimization, type D personality and the combination of domestic violence victimization and type D personality) were distal from each other. This statistic is more robust to violations of assumptions than others, such as Wilks' lambda (e.g., Tabachnick and Fidell 2007). The value of partial eta squared was checked to evaluate effect sizes. Univariate F tests with Bonferroni correction (alpha level should be $p<$ 0.025 ) were employed to identify overall group differences on the separate loneliness scales. Additionally, mean loneliness scores were plotted to inspect the manner in which victimization and type D personality interacted. All statistical analyses were performed using the software package SPSS 16.0 for Windows (SPSS Inc., Chicago, Illinois).

\section{Results}

\section{Descriptive Statistics}

Thirty-five respondents were excluded from statistical analyses due to missing data. Thus, our sample contained 625 participants. A description of the total study sample is presented in Table 1. Fifty-five (8.8\%) participants could be classified as victims of domestic violence and 134 (21.4\%) as type Ds. Twenty-one victims (3.4\%) had type D personality. Significant between-group differences were found for gender, ethnic background, marital status, having children under the age of 18 in the household, and employment status (all $p$ values $<0.05$ ). 
Table 1 Sample characteristics $(N=625)$

\begin{tabular}{|c|c|c|}
\hline Age & $\begin{array}{l}M \\
46.1 \\
n\end{array}$ & $\begin{array}{l}S D \\
11.7 \\
\% \text { of } N\end{array}$ \\
\hline \multicolumn{3}{|l|}{ Gender } \\
\hline Male & 296 & 47.4 \\
\hline \multicolumn{3}{|l|}{ Marital status } \\
\hline Married/registered partnership & 340 & 54.4 \\
\hline Cohabitating & 106 & 17.0 \\
\hline \multicolumn{3}{|l|}{ Education } \\
\hline University degree (i.e., master degree) & 67 & 25.3 \\
\hline $\begin{array}{l}\text { Higher vocational education } \\
\text { (i.e., bachelor degree) } \\
\text { Children }<18 \text { years in household }\end{array}$ & 145 & 23.2 \\
\hline$<4$ years & 77 & 12.3 \\
\hline$<12$ years & 116 & 18.6 \\
\hline$<17$ years & 99 & 15.8 \\
\hline \multicolumn{3}{|l|}{ Employment status } \\
\hline Holding a fulltime $(32-40 \mathrm{~h})$ & 308 & 49.3 \\
\hline Holding a parttime job & 141 & 22.6 \\
\hline $20-32 \mathrm{~h}$ & 91 & 14.6 \\
\hline $12-20 \mathrm{~h}$ & 34 & 5.4 \\
\hline$<12 \mathrm{~h}$ & 16 & 2.6 \\
\hline \multicolumn{3}{|l|}{ Ethnic origin } \\
\hline Dutch & 584 & 93.4 \\
\hline
\end{tabular}

\section{Between-Groups Differences for Total Loneliness Scores}

ANOVA showed a significant overall effect for the group variable after controlling for background differences, $F$ (3, $620)=57.0, p<0.001$. The value for partial Eta squared (0.216) indicated a large effect size (cf. Cohen 1988). As expected, victims with type D personality reported the highest loneliness scores $(M=7.6, S D=3.8)$, while the lowest scores were observed for nonvictims without type D personality $(M=1.9, S D=2.3)$. Also in line with expectations, type Ds without history of domestic violence $(M=$ $4.5, S D=3.4)$ and victims without type D personality $(M=$ 3.8, $S D=3.8)$ suffered from intermediate levels of loneliness (see also Fig. 2). Except from the difference between the latter two groups, which was not significant, all between-groups differences were significant at $p .<0.001$.

Emotional and Social Loneliness by Type D Personality and Domestic Violence Victimization

In addition to main effects for domestic violence victimization (Pillai's Trace $=0.07, F[2,620]=23.2, p<0.001$, partial eta squared $=0.07$ ) and type D personality (Pillai's Trace $=0.11, F[2,620]=38.4, p<0.001$, partial eta squared $=0.11$, the MANOVA on the two loneliness

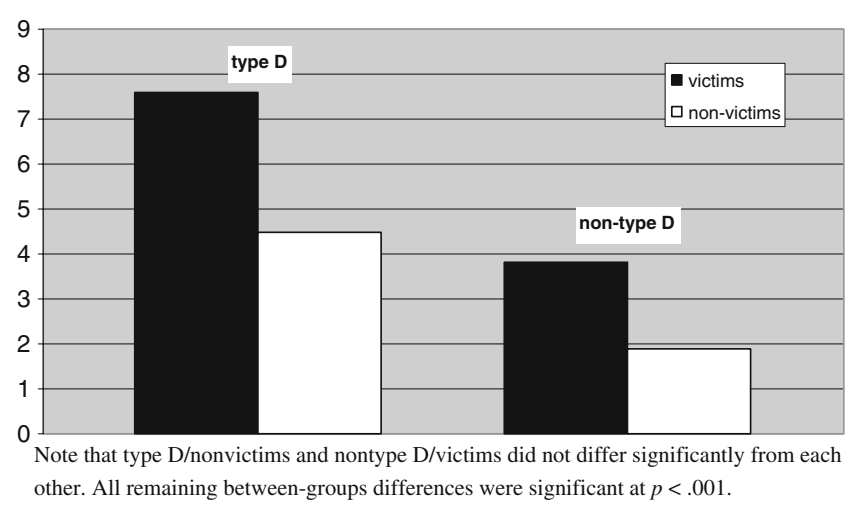

Fig. 2 Mean total loneliness scores differentiated by type D personality and victim status. Note that type D/nonvictims and nontype $\mathrm{D} /$ victims did not differ significantly from each other. All remaining between-groups differences were significant at $p<0.001$

subscales scales revealed a significant interaction between domestic violence victimization and type $\mathrm{D}$ personality, Pillai's Trace $=0.022, F(2,620)=6.95, p<0.005$, although the value for partial eta squared (0.022) suggested that the effect size of the interaction effect was small (Cohen 1988). As expected, when results for the dependent variables were considered separately in subsequent ANOVAs, the interaction effect remained significant for emotional loneliness only, $F(1,621)=18.9, p<0.005$. Bar graphs of type $\mathrm{D}$ personality by domestic violence history suggested that type Ds were at increased risk of reporting emotional loneliness when exposed to domestic violence (see Fig. 3).

\section{Discussion}

The present study was developed to test whether mean loneliness scores between individuals with type D personality and nontype Ds varied by domestic violence victimization and whether an interaction effect between type D

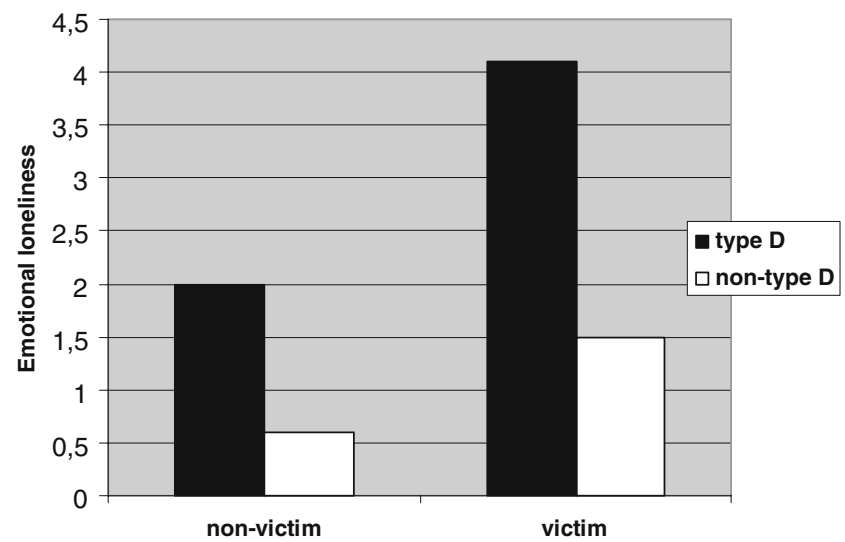

Fig. 3 Mean Emotional loneliness scores in type Ds and nontype Ds differentiated by victim status 
personality and victim status could be established. In line with expectations, type Ds with a history of domestic violence reported the highest levels of loneliness. Moreover, results suggested that emotional loneliness scores were not solely due to the accumulation of the adverse effects of type D personality and victimization history, but also due to the synergy between these two factors. In other words, the specific combination of trait NA and SI was associated with an increased risk of suffering from emotional loneliness when exposed to domestic violence.

Our results correspond with those reported by Williams and colleagues (2008). They showed that type D personality was associated with low levels of perceived quality of social support received by family and close friends in a sample of healthy university student from the United Kingdom and Ireland (Williams et al. 2008). In order to prevent mental illness or further disease development in victims of domestic violence, victim support agencies may employ our results (if these are replicated and extended in more rigorous and prospective studies) to target loneliness by tailoring services to victims' characteristic emotionregulation strategies. Currently, victims in need of psychological support are often (by default) offered the opportunity to participate in a peer support group (PSG). It is widely assumed that the adverse outcomes of victimization experiences can be overcome through participation in PSGs, for they provide the opportunity to share negative experiences with others (see Craig-Henderson and Sloan 2003). However, this supposition is merely anecdotal in nature and lacks empirical validation (cf. Hogan et al. 2002; Winkel 2006). Moreover, it is too general to be of help for all victims. Particularly victims with type $\mathrm{D}$ personality will experience PSGs as highly distressful if the setting in which they take place is not perceived as safe and secure enough to freely exhibit and be oneself - a core condition that needs to be fulfilled in order to circumvent their tendency to withdraw in social interactions. Such victims are most likely to profit from PSGs which are exclusively accessible to members of the victims' inner circle of relatives and close friends (cf. Kunst et al. 2010). If intimate support groups prove to be distressful as well or if they prove to be unfeasible (for example when the victim stays in a shelter), alternative treatment methods, such as internet-based interventions (IBIs) or structured writing therapy (SWT), should be considered. Both have been developed to avoid emotional expression in the presence of (significant) others and therapists and may therefore be particularly suitable for individuals with type D personality (cf. Kunst et al. 2011). Both IBIs and SWT have been shown to result in mental health improvement (Hirai and Clum 2005; Litz et al. 2007; Van Emmerik et al. 2008). Given the high prevalence rate of type $\mathrm{D}$ personality among victims of domestic violence observed in this study $(21 / 55,38.2 \%)$, the benefits of any of these alternative support modalities are likely to outweigh their costs.

\section{Study Limitations}

When interpreting our study's results, several limitations need to be considered. First, due to the cross-sectional nature of our data, we were not able to establish cause and effect. Most importantly, this made it impossible to properly test for the moderating impact of type $\mathrm{D}$ personality on the relationship between domestic violence victimization and loneliness. Second, the psychometric properties of our measure of domestic violence victimization are unknown. In the current study, only $8.8 \%$ of participants had been victimized during the last year. Presumably due to administration of different instruments; differences in reference periods used; and inclusion of women only, other studies have found much higher prevalence rates (e.g., Garcia-Moreno et al. 2006; Rivera-Rivera et al. 2004; Coker et al. 2000). Third, our data set did not contain information on, among other things, the experience of other stressful events, timing of victimization, and the perceived severity of the acts of violence under investigation. Each of these factors may have affected loneliness. Moreover, the data set did not allow controlling for other personality characteristics than the combination of NA and SI. Consequently, the divergent validity of type D personality with related personality constructs could not be determined. Faultfinders have argued that type D personality adds nothing new to "the maze of concepts" (Garssen 2007, p. 471) playing a role in the etiology of health-related problems and is just another measure of NA, neuroticism (Lesperance and Frasure-Smith 1996), or the anxious defensive style (Garssen 2007). To refute such arguments, Denollet (2000, p. 258) has emphasized that "within the type D framework, NA [or related constructs, such as neuroticism] refers to a continuous personality trait (...) while 'distressed' refers to a discrete (italics by author) personality configuration designating patients who are inclined to experience emotional and interpersonal difficulties". In support of this view, Williams and colleagues (2008) have shown that type D personality was associated with low levels of perceived social support when adjusting for a continuous variable of neuroticism in a sample of healthy young adults. However, future studies are needed to replicate these findings and to determine their validity with regard to other outcomes. Fourth, the failure to document a significant interaction between type D personality and history of domestic violence on social loneliness was expected, but may lack generalizability, for example to sheltered populations. Several studies suggest that victims of domestic violence who stay in shelters experience loneliness differently from subjects recruited among the 
general population (Arokach 2006; Rokach 2006, 2007). Fifth, the response rate in our study was rather low. This may have biased the study's results. Finally, our sample mainly included participants of Dutch origin. Since a number of studies suggest that antecedents of loneliness vary by cultural background (e.g., Rokach 1998), this study characteristic may have influenced our findings as well.

Despite these limitations, our study was the first to investigate the association between domestic violence victimization, Type D personality, and loneliness. By doing so, we extended the slowly growing body of research focusing on the interplay of different global personality traits and health outcomes (Denollet 2000; Grant, and Langan-Fox 2006). Looking beyond the traditional question of how single traits affect disease and instead adopt an approach that takes into account the ways different traits interact to elicit adverse health consequences may help the identification of those most at risk for adverse outcomes when faced with highly stressful situations or events (cf. Denollet 1997). Finally, it was the first study to test for the significance of the association between the interaction of type D personality and domestic violence victimization and loneliness. Future studies may consider replication of our findings with prospective data. Of particular interest is an examination of type $\mathrm{D}$ personality prior to victimization and loneliness. To test for the full model proposed in the introduction section of this paper, their design should also allow for the assessment of mental health problems.

Acknowledgement The authors are grateful for the research support from the Hart voor Brabant Health Service. In particular, we want to thank Gemma Smulders for her explanation of the questionnaire and assessment procedure.

Open Access This article is distributed under the terms of the Creative Commons Attribution Noncommercial License which permits any noncommercial use, distribution, and reproduction in any medium, provided the original author(s) and source are credited.

\section{References}

Arokach, A. (2006). Alienation and domestic abuse: How abused women cope with loneliness. Social Indicators Research, 78, 327-340.

Asendorpf, J. B. (1993). Social inhibition: A general-developmental perspective. In H. C. Traue \& J. W. Pennebaker (Eds.), Emotion, inhibition, and health (pp. 80-99). Seattle: Hogrefe \& Huber.

Chipuer, H. M. (2001). Dyadic attachments and community connectedness: Links with youths' loneliness experiences. Journal of Community Psychology, 29, 429-446.

Cohen, J. (1988). Statistical power for the behavioral sciences. Hillsdale: Erlbaum.

Coker, A. L., Smith, P. H., Bethea, L., King, M. R., \& McKeown, R. E. (2000). Physical health consequences of physical and psychological intimate partner violence. Archives of Family Medicine, 9, 451-457.
Craig-Henderson, K., \& Sloan, L. R. (2003). After the hate: Helping psychologists help victims of racist hate crime. Clinical Psychology: Science and Practice, 10, 481-490.

De Jong Gierveld, J. (1987). Developing and testing a model of loneliness. Journal ofPersonality and Social Psychology, 53, 119-128.

De Jong Gierveld, J., \& Kamphuis, F. (1985). The development of a Rasch-type loneliness scale. Applied Psychological Measurement, 9, 289-299.

De Jong Gierveld, J., Van Tilburg, T., \& Dykstra, P. A. (2006). Loneliness and social isolation. In A. Vangelisti \& D. Perlman (Eds.), Cambridge handbook of personal relationships (pp. 485500). Cambridge: Cambridge University Press.

Denollet, J. (1997). Personality, emotional distress and coronary heart disease. European Journal of Personality, 11, 343-357.

Denollet, J. (2000). Type D personality: A potential risk factor refined. Journal of Psychosomatic Research, 49, 255-266.

Denollet, J. (2005). Standard assessment of negative affectivity, social inhibition, and type D personality. Psychosomatic Medicine, 67, 89-97.

Denollet, J., Sys, S. U., \& Brutsaert, D. L. (1995). Personality and mortality after myocardial infarction. Psychosomatic Medicine, 57, 582-591.

Denollet, J., Sys, S. U., Stroobant, N., Rombouts, H., Gillebert, T. C., et al. (1996). Personality as independent predictor of long-term mortality in patients with coronary heart disease. Lancet, 347, 417-421.

Dykstra, P. A., Van Tilburg, T. G., \& De Jong Gierveld, J. (2005). Changes in older adult loneliness: Results from a seven-year longitudinal study. Research on Aging, 27, 725-747.

Emons, W. H. M., Meijer, R. R., \& Denollet, J. (2007). Negative affectivity and social inhibition in cardiovascular disease: Evaluating type D personality and its assessment using item response theory. Journal of Psychosomatic Research, 63, 27-39.

Garcia-Moreno, C., Jansen, H. A. F. M., Ellsberg, M., Heise, L., \& Watts, C. H. (2006). Prevalence of intimate partner violence: findings from the WHO multi-country study on women's health and domestic violence. Lancet, 368, 1260-1269.

Garssen, B. (2007). Repression: Finding our way in the maze of concepts. Journal of Behavioral Medicine, 30, 471-481.

Grant, S., \& Langan-Fox, J. (2006). Occupational stress, coping and strain: The combined/interactive effect of the Big Five traits. Personality and Individual Differences, 41, 719-732.

Hawthorne, G. (2008). Perceived social isolation in a community sample: its prevalence and correlates with aspects of peoples' lives. Social Psychiatry and Psychiatric Epidemiology, 43, 140150.

Hirai, M., \& Clum, G. A. (2005). An internet-based self-change program for traumatic event related fear, distress, and maladaptive coping. Journal of Traumatic Stress, 18, 631-636.

Hogan, B. E., Linden, W., \& Najarian, B. (2002). Social support interventions: Do they work? Clinical Psychology Review, 22, 381-440.

Jones, L. M., Robles, T., Kiecolt-Glaser, J. K., Malarkey, W. B., \& Glaser, R. (2005). Loneliness moderates the effects of chronic stress on the immune response to a pneumococcal pneumonia vaccine. Brain, Behavior, and Immunity, 19(4, Supplement 1), e34-e34.

Kitzmann, K. M., Gaylord, N. K., Holt, A. R., \& Kenny, E. D. (2003). Child witnesses to domestic violence: A meta-analytic review. Journal of Consulting and Clinical Psychology, 71, 339-352.

Kunst, M. J. J., Bogaerts, S., \& Winkel, F. W. (2009). Peer and inmate aggression, type D- personality and post-traumatic stress among Dutch prison workers. Stress and Health, 25, 387-395.

Kunst, M., Bogaerts, S., \& Winkel, F. W. (2010). Domestic violence and mental health in a Dutch community sample: The adverse 
role of loneliness. Journal of Community \& Applied Social Psychology, 20, 419-425.

Kunst, M. J. J., Bogaerts, S., \& Winkel, F. W. (2011). Type D personality and posttraumatic stress disorder in victims of violence: a cross-sectional exploration. Clinical Psychology \& Psychotherapy, 18, 13-22.

Lauder, W., Sharkey, S., \& Mummery, K. (2004). A community survey of loneliness. Journal of Advanced Nursing, 46, 88-94.

Lesperance, F., \& Frasure-Smith, N. (1996). Negative emotions and coronary heart disease: getting to the heart of the matter. Lancet, 347, 414-415.

Litz, B. T., Engel, C. C., Bryant, R. A., \& Papa, A. (2007). A randomized, controlled proof- of-concept trail of an internetbased, therapist-assisted self-management treatment for posttraumatic stress disorder. The American Journal of Psychiatry, 164, 1676-1684.

Nurius, P. S., Macy, R. J., Bhuyan, R., Holt, V. L., Kernic, M. A., \& Rivara, F. P. (2003). Contextualizing depression and physical functioning in battered women: Adding vulnerability and resources to the analysis. Journal of Interpersonal Violence, 18, $1411-1431$

Okour, A., \& Hijazi, H. (2009). Domestic violence and family dysfunction as risk factor for violent behavior among university students in North Jordan. Journal of Family Violence, 24, 361366.

Olson, C. L. (1979). Practical considerations in choosing a MANOVA test statistic: a rejoinder to Stevens. Psychological Bulletin, 86, $1350-1352$

Peplau, L. A., \& Perlman, D. (1982). Perspectives on loneliness. In L. A. Peplau \& D. Perlman (Eds.), Loneliness: A sourcebook of current theory, research, and therapy (pp. 1-16). New York: Wiley.

Rivera-Rivera, L., Lazcano-Ponce, E., Salmerón-Castro, J., SalazarMartínez, E., Castro, R., \& Hernández-Avila, M. (2004). Prevalence and determinants of male partner violence against Mexican women: A population-based study. Salud Pública de México, 46(2), 113-122.

Rokach, A. (1998). The relation of cultural background to the causes of loneliness. Journal of Social and Clinical Psychology, 17, 7588.

Rokach, A. (2006). Loneliness in domestically abused women. Psychological Reports, 98, 367-373.

Rokach, A. (2007). Loneliness and intimate partner violence: Antecedents of alienation of abused women. Social Work in Health Care, 45, 19-31.

Römkens, R. (1997). Prevalence of wife abuse in the Netherlands: Combining quantitative and qualitative methods in survey research. Journal of Interpersonal Violence, 12, 99-125.

Ruiz-Pérez, I., Plazaola-Castaño, J., \& Del Río-Lozano, M. (2007). Physical health consequences of intimate partner violence in Spanish women. European Journal of Public Health, 17, 437443.

Scott, S., \& Babcock, J. (2010). Attachment as a moderator between intimate partner violence and PTSD symptoms. Journal of Family Violence, 25, 1-9.

Staggs, S. L., Long, S. M., Mason, G. E., Krishnan, S., \& Riger, S. (2007). Intimate partner violence, social support, and employment in the post-welfare reform era. Journal of Interpersonal Violence, 22, 345-367.
Swick, K. (2008). The dynamics of violence and homelessness among young families. Early Childhood Education Journal, $36,81-85$.

Tabachnick, B. G., \& Fidell, L. S. (2007). Using multivariate statistics (5th ed.). Boston: Allyn and Bacon/Pearson Education.

Tull, M. T., Jakupcak, M., McFadden, M. E., \& Roemer, L. (2007). The role of negative affect intensity and the fear of emotions in posttraumatic stress symptom severity among victims of childhood interpersonal violence. The Journal of Nervous and Mental Disease, 195, 580-587.

Vaux, A. (1988). Social and emotional loneliness. Personality and Social Psychology Bulletin, 14, 722-734.

Van Dijk, T., Flight, S., Oppenhuis, E., \& Duesmann, B. (1998). Domestic violence: A national study of the nature, size, and effects of domestic violence in the Netherlands. European Journal on Criminal Policy and Research, 6, 7-35.

Van Emmerik, A. A. P., Kamphuis, J. H., \& Emmelkamp, P. M. G. (2008). Treating acute stress disorder and posttraumatic stress disorder with cognitive behavioral therapy or structured writing therapy: A randomized controlled trial. Psychotherapy and Psychosomatics, 77, 93-100.

Van Tilburg, T. G., \& De Leeuw, E. D. (1991). Stability of scale quality under various data collection procedures: A mode comparison of the de Jong Gierveld loneliness scale. International Journal of Public Opinion Research, 3, 69-85.

Watson, D., \& Clark, L. A. (1984). Negative affectivity: the disposition to experience aversive emotional states. Psychological Bulletin, 96, 465-490.

Watson, D., \& Pennebaker, J. W. (1989). Health complaints, stress, and distress: exploring the central role of negative affectivity. Psychological Review, 96, 234-54.

Weiss, R. S. (1973). The experience of emotional and social isolation. Cambridge: MIT.

Weiss, R. S. (1974). The provisions of social relationships. In Z. Rubin (Ed.), Doing unto others (pp. 17-26). Englewood Cliffs: Prentice Hall.

Wet collectieve preventie volksgezondheid van 1990 [Dutch Public Health Preventive Measures Act of 1990].

Williams, L., O’Connor, R. C., Howard, S., Hughes, B. M., Johnston, D. W., Hay, J. L., et al. (2008). Type D personality mechanisms of effect: The role of health-related behaviour and social support. Journal of Psychosomatic Research, 64, 63-69.

Winkel, F. W. (2006). Peer support groups: Evaluating the mere contact/mere sharing model and impairment hypotheses. International Perspectives in Victimology, 2, 101-113.

Winkel, F. W. (2007). Posttraumatic anger: missing link in the wheel of misfortune. Inaugural speech Tilburg University. Nijmegen, The Netherlands: Wolf Legal Publishers.

Wolfe, D. A., Crooks, C. V., Lee, V., McIntyre-Smith, A., \& Jaffe, P. G. (2003). A meta- analysis of the effects of children's exposure to domestic violence: The need for a developmental framework. Clinical Child and Family Psychology Review, 6, 171-187.

Zeidner, M. (2006). Individual differences in psychological reactions to terror attack. Personality and Individual Differences, 40, 771781.

Zlotnick, C., Kohn, R., Peterson, J., \& Pearlstein, T. (1998). Partner physical victimization in a national sample of American families: Relationship to psychological functioning, psychosocial factors, and gender. Journal of Interpersonal Violence, 13, 156-166. 